\title{
A Case Report on serendipitous diagnosis of Wilson's Disease in a child with Brucellosis and Pseudomonal Infection
}

\author{
Kiran Malbul ${ }^{1}$, Srijana Katwal ${ }^{1}$, Saurav Khetan ${ }^{2}$, and Nirjala Aryal $^{2}$ \\ ${ }^{1}$ Nepalese Army Institute of Health Sciences College of Medicine \\ ${ }^{2}$ Birendra Military Hospital
}

October 26, 2020

\begin{abstract}
We herein report a rare case of Wilson disease in a 9 years old girl, diagnosed incidentally while investigating the cause of deterioration of condition even after standard of care for Brucellosis. The case provides a glimpse on intricacy of diagnosing Wilson disease in a child with superimposed infection.
\end{abstract}

\section{A case report on Serendipitous Diagnosis of Wilson's Disease in a Child with Brucellosis and} Pseudomonal Infection

Kiran Malbul, ${ }^{1}$ Srijana Katwal, ${ }^{1}$ Saurav Khetan, ${ }^{2}$ Nirjala Shrestha ${ }^{2}$

${ }^{1}$ Nepalese Army Institute of Health Sciences College of Medicine, Sanobharyang, Kathmandu, Nepal

${ }^{2}$ Department of Pediatrics, Shree Birendra Hospital, Chhauni, Kathmandu, Nepal

\section{Corresponding author :}

Kiran Malbul, Nepalese Army Institute of Health Sciences College of Medicine, Sanobharyang, Kathmandu, Nepal Email: kiran.malbul04@naihs.edu.np, Phone: +977 9861182313

\section{Key clinical message:}

This case depicts the necessity of suspicion of Wilson's disease in variable presentation of liver disorders, especially in pediatrics population and encourages us to be more judicious in using hepatotoxic medications in it.

Keywords: Brucellosis; Coinfection; D-Penicillamine; Pediatric; Rifampin; Wilson's disease

\section{INTRODUCTION}

Wilson's disease (WD) is an inherited rare autosomal recessive genetic defect of copper metabolism which frequently leads to progressive hepatolenticular degeneration and is often characterized by hepatic and neurological manifestation. ${ }^{1}$ It is observed with a prevalence of approximately 1 case per 30,000 live births with an estimation of high prevalence in the East Asian region. ${ }^{2,3}$ Wilson's disease is an outcome of a mutation in ATP7B, a gene encoding a copper transport protein on chromosome $13 .{ }^{4,5}$ The ATP7B helps in the transport of copper into the trans-Golgi compartment and combine it into caeruloplasmin and excretes excess amount into the bile. Defective ATP7B leads to accumulation of copper into tissues, ${ }^{1}$ resulting in various clinical manifestations predominantly hepatic, neurological and psychiatric with at times the presence of KayserFleischer rings on the cornea, often many patients having a combination of symptoms. ${ }^{6-8}$ Early clinical features are nonspecific and sometimes maybe misleading in establishing a definitive diagnosis especially in 
young patients and with concurrent other infections. Therefore, in young patients with unclear liver disease, hematologic or neurologic disorders a differential diagnosis of Wilson's disease must be excluded. ${ }^{6}$ We report a rare case of Wilson's disease in a 9 years old girl presented initially with fever and progressive yellowish discoloration of the body, later confirmed to be having Wilson's disease with acute on chronic liver failure with brucellosis and culture-positive Pseudomonasinfection and also illustrate the complexity of diagnosing Wilson's disease in the early stages of a clinical course complicated with infection.

\section{CASE PRESENTATION}

A 9 years old girl with normal birth and development history, previously asymptomatic, presented with complaints of fever and jaundice for 10 days. As per her parents, she was initially taken to a nearby hospital where on investigations revealed child having severe anemia with hemoglobin $3.4 \mathrm{gm} / \mathrm{dl}$. For that she was suspected and worked up on the line of hemolytic condition and was transfused with 2 pints of packed RBCs then referred to our center for further evaluation.

On admission, her mother stated that her child developed intermittent fever with chills and rigor 10 days ago with maximum documented temperature being $102^{*} \mathrm{~F}$. In addition, she gave history of progressive yellowish discoloration of skin, pain on right upper abdominal quadrant and pale appearance over time. She did not provide any history of child having nausea, vomiting, excessive itchiness, passage of clay colored stool or any rashes and bleeding from any sites. She denied of child ingesting any medications, fava beans or child having any known previous medical and surgical conditions. Her parents also denied of consanguineous marriage and did not provide any significant past history and nutritional history. Both parents also stated that her child was immunized as per her schedule of her birth year.

On examination, she was ill looking with presence of icterus and pallor, her recorded temperature was $98.5^{*} \mathrm{~F}$. Per abdominal examination revealed tender hepatomegaly with liver span of $14 \mathrm{~cm}$, liver being firm in consistency and smooth surfaced with regular borders and splenomegaly with lower border palpable $1 \mathrm{~cm}$ below the left subcostal margin. Other systemic examinations were normal.

Laboratory studies are listed in Table 1 . As the child was admitted to the pediatric ward, baseline investigations were sent which were suggestive of direct coombs test (DCT) negative hemolytic anemia; hemoglobin $8.4 \mathrm{gm} / \mathrm{dl}$ (reference 11.5-15.5 gm/dl) with raised total and unconjugated bilirubin ; 16.3 and $6.9 \mathrm{mg} / \mathrm{dl}$ (reference $0.2-1 \mathrm{mg} / \mathrm{dl},<0.35 \mathrm{mg} / \mathrm{dl}$ ) respectively, raised Prothrombin time 18.3 seconds (reference 12.2-15.5 seconds) but normal INR and liver enzymes. On the 3rd day of her admission, investigations showed raised brucella titer 1:160 (significant titer $>=1: 80$ ) that was treated with Rifampicin and Doxycycline and positive blood culture forPseudomonas infection treated according to culture sensitivity. On $14^{\text {th }}$ day of her admission investigations showed anemia with hemoglobin $10 \mathrm{gm} / \mathrm{dl}$ (reference 11.5-15.5 gm/dl) with raised total bilirubin and unconjugated bilirubin ; 5.13 and $3.27 \mathrm{mg} / \mathrm{dl}$ (reference $0.2-1 \mathrm{mg} / \mathrm{dl},<0.35 \mathrm{mg} / \mathrm{dl}$ ) respectively and significantly raised aspartate aminotransferase $336 \mathrm{U} / \mathrm{L}$ (reference 15-40 U/L), alanine aminotransferase 237 U/L (reference 10-36 U/L), alkaline phosphatase 158U/L (reference 30-120 U/L), Prothrombin time 28.3 seconds (reference 12.5-15.5 sec) and International Normalized ratio of 1.9 (reference 0.8-1.2) after which rifampin had to be withdrawn. Abdominal ultrasonography revealed hepatomegaly with coarse echotexture, mild splenomegaly and minimal ascites suggesting features of chronic liver disease. On $22^{\text {nd }}$ day of admission on investigating for Wilson's disease and autoimmune hepatitis her serum ceruloplasmin was found to be decreased $9.18 \mathrm{mg} / \mathrm{dl}$ (reference $23-51 \mathrm{mg} / \mathrm{dl}$ ) with significantly raised 24-hour urinary copper $2069 \mathrm{mi}-$ crogram/day (reference 3-50 microgram/day) which provided an evidence for Wilson's disease, anti-nuclear antibodies and anti-dsDNA were negative. Fibro scan showed normal CAP score of $227 \mathrm{~dB} / \mathrm{m}(<238 \mathrm{~dB} / \mathrm{m})$ but fibrosis score of $24.4 \mathrm{kPa}$ was suggestive of advanced liver scarring (in range of F4) Figure 1. Upper GI Endoscopy was normal. Eye evaluation showed no evidence of Kayser-Fleischer rings. Genetic testing for mutated gene was not done due to financial constraints. Both the parents were also investigated for KayserFleischer ring but was negative and liver function tests were normal. On her $23^{\text {rd }}$ day, after the initiation of D-Penicillamine and 9 days after the stoppage of rifampin, her liver function tests showed progressive improvement with normalizing prothrombin time and international normalized ratio. Her clinical conditions and laboratory parameters showed progressive improvement with near normal liver functions tests before 
her discharge.

\section{TREATMENT}

Initially, our treatment was directed in the line of infection. Hence, cefotaxime and azithromycin were continued as provided at primary hospital initially and with definitive diagnosis of brucellosis and pseudomonal infection, therapy was switched to cefepime, doxycycline and rifampin on the standard of care. However, rifampin was discontinued on day 14 due to deterioration of clinical condition with progressive derangement in the liver function tests in view of drug induced liver injury. For that, Vitamin K $10 \mathrm{mg}$ was added. The child developed two episodes of fever on $16^{\text {th }}$ and $17^{\text {th }}$ day, so on $17^{\text {th }}$ day antibiotics were upgraded with Meropenem and Vancomycin along with Fluconazole. Later, on diagnosing Wilson's disease, the patient was started on D-Penicillamine and Zinc with Pyridoxine. With clinical improvement of the case and no fresh complaints, patient was discharged on day 40 with a prescription containing D- Penicillamine, zinc, pyridoxine for 1 month and doxycycline for 6 days.

\section{OUTCOME AND FOLLOWUP}

Patient's clinical conditions improved with normalization of laboratory parameters mainly liver function tests. Subsequently she was discharged with medical therapy with a plan to follow up after 3 months.

\section{DISCUSSION}

Wilson disease is a rare autosomal recessive disorder having broad range of age of presentation ranging from 3-55 years. ${ }^{9}$ and can present with extreme diversity in the clinical manifestation from asymptomatic to various hepatic, neurological, psychiatric, hematological and ophthalmological manifestation. ${ }^{1,8,10}$ This often causes convolutions in the diagnosis of case leading to the diagnostic dilemmas.

At birth, children with Wilson disease are usually normal and may remain asymptomatic for variable period of time. ${ }^{11,12}$ In the meantime, the copper gradually gets deposited in the liver followed by pouring of excess amount into the circulation and then gradually accumulates in extra-hepatic tissues like brain and Descemet's membrane of cornea. ${ }^{13,14}$ Thus, liver manifestations are more common in first decade of life whereas neurological manifestations are common in third decades. ${ }^{1,15}$ Liver is presumed to have considerable capacity to store excess copper hence, clinical manifestations are barely observed before 3 years of age. ${ }^{10,16}$ Data from numerous pediatric series showed 9- 10 years of age as average age of diagnosis of the disease. ${ }^{7}$ Supporting the data our case of Wilson disease was also presented in a girl on her first decade of life, she is being 9 years old.

Not all cases in Wilson's disease present with typical hepatic, neurological, and psychiatric manifestations with Kayser- Fleischer ring. Various studies have suggested that only clinical and laboratory parameters are insufficient to diagnose Wilson's disease in patients with liver disease of unknown origin. ${ }^{10,14,17}$ In a series of cases studied by Nina Manolakit et al (2009). out of 57 cases, $25 \%$ presented with jaundice, $12 \%$ with acute coombs negative hemolytic anemia.; Only $38 \%$ of patient had KF ring. ${ }^{18}$ Similarly in a study done by steindl et al (1997). out of 55 cases, serum ceruloplasmin level was $<20 \mathrm{mg} / \mathrm{dL}$ in $73 \%$, urinary copper excretion was increased in $88 \%$, and liver copper content was elevated in $91 \%$ at diagnosis. Kayser- Fleischer rings were detected in $55 \%$. In contrast to patients with neurological disease (90\% Kayser- Fleischer rings, $85 \%$ low ceruloplasmin), only $65 \%$ of patients presenting with liver disease were diagnosed by these typical findings. ${ }^{17}$

In some cases, Wilson disease becomes an incidental finding while investigating for other health issues like infections. ${ }^{7}$ This is a case of 9 years old girl presented with acute onset of fever, jaundice, severe direct coombs test negative hemolytic anemia, right upper quadrant abdominal pain and hepato-splenomegaly whose work up was first directed towards infective line revealing brucellosis and Pseudomonas positive blood culture. She was then treated with cefepime, doxycycline and rifampin; nonetheless, her condition worsened 9 days after the start of antibiotics with aggravation of symptoms and increasing abnormality in liver function tests showed by raised liver enzymes and impaired international normalized ratio, unimproved by vitamin $\mathrm{K}$ administration . This suggested onset of acute liver failure in our case which generated the curiosity towards 
possible liver disorder and the workups in that line later revealed the features of chronic liver disease. ${ }^{19,20}$ In that view, a suspicion was made for the possibility of Wilson disease or other autoimmune liver diseases, investigations done on the possible differential diagnosis later established the diagnosis of Wilson's disease in our case. Moreover, improvement in the condition of our case after providing D-penicillamine and zinc on $7^{\text {th }}$ day, a treatment of Wilson disease, added optimistic note on our diagnosis. Similar findings have been reported in the study done by Chaudhari S et al. where 45 out of 50 cases showed satisfactory response to D- penicillamine and zinc therapy. ${ }^{15}$

In children, hemolysis may be an initial presentation of Wilson's disease which might apparently get precipitated by infections or drugs and mostly is transient and self-limiting , resulting in brief episodes of jaundice. ${ }^{7}$ Our patient might be in latent phase of Wilson's disease till she got infected with brucellosis. The infection might have triggered severe DCT negative hemolytic anemia resulting progressive jaundice. In addition, intake of hepatotoxic drugs like doxycycline and rifampin might have aggravated the condition giving rise to progressive abnormal liver functions test suggestive of acute on chronic liver injury. ${ }^{21,22,23,24}$ Besides liver manifestation, patient had no neurological manifestations and absent Kayser-Fleischer rings on cornea. This is in accordance with the study done by Kalamar et al. where one patient presented with hepatic lesions but did not reveal Kayser- Fleischer ring and neurological manifestations. ${ }^{25}$

A positive family history, detectable Kayser-Fleischer rings, low ceruloplasmin level $(<20 \mathrm{mcg} / \mathrm{dL})$, free copper $>25 \mathrm{mcg} / \mathrm{dL}$, and $24 \mathrm{hr}$ urine copper $>100 \mathrm{mcg} / 24 \mathrm{~h}$ are some parameters which can direct to the diagnosis of Wilson disease. ${ }^{26}$ Our patient had low serum ceruloplasmin $(<9.18 \mathrm{mg} / \mathrm{dl})$ and high 24 hour urinary copper (2069 microgram/day). However, till date no gold standard test has been established to diagnose Wilson's disease hence, the diagnosis should be based on combination of clinical presentation, laboratory results and mutation analysis. ${ }^{14,18}$ Modified Leipzig score is useful in patients presenting with liver disease with inconclusive diagnosis where the cumulative score of four or above establishes the diagnosis of Wilson disease which in our case was 5 (serum ceruloplasmin $6-11 \mathrm{mg} / \mathrm{dl}-2$, 24-hour urinary copper $>100 \mathrm{mcg}-2$, Coombs-negative hemolytic anemia with liver disease -1 ). This strongly directs our case as Wilson disease. ${ }^{8}$

Hence this is an incidentally diagnosed case of acute on chronic hepatic Wilson's disease detected while working for finding the cause of ineffectiveness of medication for brucellosis rather leading to degradation of the conditions.

\section{CONCLUSIONS}

In summary, Wilson's disease is a treatable disease which needs clinical focus with combined investigations to diagnose it on time and prevent mortality and morbidity from it. This case carries weightage to depict the importance and necessity of suspicion of Wilson's disease in variable presentation of liver disorders, especially in pediatrics population. It also encourages us to be more cautious in using hepatotoxic medications in cases of diagnosed or suspected liver disorders like Wilson's disease.

\section{AUTHORSHIP LIST}

1. Kiran Malbul

2. Srijana Katwal

3. Saurav Khetan

4. Nirjala Aryal

\section{AUTHORS CONTRIBUTIONS:}

Kiran Malbul, Srijana Katwal were involved in conception of the study, acquisition of data, drafting and reshaping the initial manuscript and revising the contents.

Saurav Khetan was involved in acquisition of data and reshaping the manuscript whereas Nirjala Aryal helped in revising the manuscript critically for important intellectual content 
All authors approved the final version of the manuscript and agreed to be accountable for all aspects of the work in ensuring that questions related to the accuracy or integrity of any part of the work are appropriately investigated and resolved.

\section{ACKNOWLEDGEMENT : None CONFLICT OF INTEREST : None CONSENT :}

written informed consent was taken from the patient's parents before writing the manuscript.

\section{REFERENCES}

1. Ala A, Walker AP, Ashkan K, Dooley JS, Schilsky ML. Wilson's disease.Lancet . 2007;369(9559):397-408. doi:10.1016/S0140-6736(07)60196-2

2. Gollan JL, Gollan TJ. Wilson disease in 1998: genetic, diagnostic and therapeutic aspects. J Hepatol . 1998;28 Suppl 1:28-36. doi:10.1016/s0168-8278(98)80373-5

3. Sandahl TD, Ott P. Chapter 7 - Epidemiology of Wilson Disease. In: Weiss KH, Schilsky MBT-WD, eds. Academic Press; 2019:85-94. doi:https://doi.org/10.1016/B978-0-12-811077-5.00007-4

4. Bull PC, Thomas GR, Rommens JM, Forbes JR, Cox DW. The Wilson disease gene is a putative copper transporting P-type ATPase similar to the Menkes gene. Nat Genet . 1993;5(4):327-337. doi:10.1038/ng1293327

5. Roberts EA, Schilsky ML. Diagnosis and treatment of Wilson disease: An update. Hepatology . 2008;47(6):2089-2111. doi:10.1002/hep.22261

6. Stremmel W, Meyerrose K-W, Niederau C, Hefter H, Kreuzpaintner G, Strohmeyer G. Wilson Disease: Clinical Presentation, Treatment, and Survival. Ann Intern Med . 1991;115(9):720-726. doi:10.7326/00034819-115-9-720

7. Roberts EA, Socha P. Wilson disease in children. Handb Clin Neurol . 2017;142:141-156. doi:10.1016/B978-0-444-63625-6.00012-4

8. Nagral A, Sarma MS, Matthai J, et al. Wilson's Disease: Clinical Practice Guidelines of the Indian National Association for Study of the Liver, the Indian Society of Pediatric Gastroenterology, Hepatology and Nutrition, and the Movement Disorders Society of India. J Clin Exp Hepatol . 2019;9(1):74-98. doi:10.1016/j.jceh.2018.08.009

9. Roberts EA, Schilsky ML. AASLD PRACTICE GUIDELINES Diagnosis and Treatment of Wilson Disease: An Update. Hepatology . 2008;47(6):2089-2111. doi:10.1002/hep.22261

10. GITLIN JD. EASL Clinical Practice Guidelines: Wilson's disease.J Hepatol . 2012;56(3):671-685. doi:10.1016/j.jhep.2011.11.007

11. Esezobor CI, Banjoko N, Rotimi-Samuel A, Lesi FEA. Wilson disease in a Nigerian child: a case report. J Med Case Rep . 2012;6(1):200. doi:10.1186/1752-1947-6-200

12. Saito T. Presenting symptoms and natural history of Wilson disease.Eur J Pediatr . 1987;146(3):261-265. doi:10.1007/BF00716470

13. Report C, Kaur H, Kaur K, Sharma N, Kumar K. Wilson's Disease - A Case Report. Int J Contemp Med Res . 2019;6(7):G42-G44.

14. Ferenci P, Caca K, Loudianos G, et al. Diagnosis and phenotypic classification of Wilson disease1. Liver Int . 2003;23(3):139-142. doi:10.1034/j.1600-0676.2003.00824.x 
15. Chaudhuri S. Wilson's Disease in Children - Experience from a Tertiary Care Centre. J Med Sci Clin Res . 2018;06(06):170-174. https://dx.doi.org/10.18535/jmscr/v6i6.29

16. WALSHE JM. Wilson's Disease Presenting with Features of Hepatic Dysfunction: A Clinical Analysis of Eighty-seven Patients. QJM An Int J Med . 1989;70(3):253-263. doi:10.1093/oxfordjournals.qjmed.a068320

17. Steindl P, Ferenci P, Dienes HP, et al. Wilson's disease in patients presenting with liver disease: a diagnostic challenge. Gastroenterology . 1997;113(1):212-218. doi:10.1016/s0016-5085(97)70097-0

18. Manolaki N, Nikolopoulou G, Daikos G, et al. Wilson Disease in Children: Analysis of 57 Cases. $J$ Pediatr Gastroenterol Nutr . 2009;48:72-77. doi:10.1097/MPG.0b013e31817d80b8

19. Lee WM, Stravitz RT, Larson AM. Introduction to the revised American Association for the Study of Liver Diseases Position Paper on acute liver failure 2011. Hepatology . 2012;55(3):965-967. doi:10.1002/hep. 25551

20. Wendon Julia, Cordoba J, Dhawan A, et al. EASL Clinical Practical Guidelines on the management of acute (fulminant) liver failure. J Hepatol . 2017;66(5):1047-1081. doi:10.1016/j.jhep.2016.12.003

21. Lienart F, Morissens F, Jacobs P, Ducobu J. Doxycycline and Hepatotoxicity. Acta Clin Belg . 1992;47(3):205-208. doi:10.1080/17843286.1992.11718230

22. Heaton PC, Fenwick SR, Brewer DE. Association between tetracycline or doxycycline and hepatotoxicity: a population based case-control study. J Clin Pharm Ther . 2007;32(5):483-487. doi:10.1111/j.13652710.2007.00853.x

23. Ichai P, Saliba F, Antoun F, et al. Acute liver failure due to antitubercular therapy: Strategy for antitubercular treatment before and after liver transplantation. Liver Transplant Off Publ Am Assoc Study Liver Dis Int Liver Transplant Soc . 2010;16(10):1136-1146. doi:10.1002/lt.22125

24. Fatal and severe hepatitis associated with rifampin and pyrazinamide for the treatment of latent tuberculosis infection-New York and Georgia, 2000. MMWR Morb Mortal Wkly Rep . 2001;50(15):289-291.

25. Kalamar V. Childhood Onset of Wilson's Disease A Case Report. Published online 2014.

26. Sócio S de A, Ferreira AR, Fagundes EDT, et al. Wilson's disease in children and adolescents: diagnosis and treatment. Rev Paul Pediatr . 2010;28:134-140.

LIST OF TABLES AND FIGURES

\begin{tabular}{llllll}
\hline $\begin{array}{l}\text { laboratory } \\
\text { investigations }\end{array}$ & Day 1- admission & $\begin{array}{l}\text { Day 14 - } \\
\text { Rifampin } \\
\text { withdrawn }\end{array}$ & $\begin{array}{l}\text { Day 23 - } \\
\text { D-penicillamine } \\
\text { started }\end{array}$ & $\begin{array}{l}\text { Day 40 - } \\
\text { discharge }\end{array}$ & Reference range \\
\hline $\begin{array}{l}\text { White blood } \\
\text { cell count } \\
(\text { cells } / \mu \lambda)\end{array}$ & 7000 & 9500 & 4300 & 6020 & $4500-11000$ \\
$\begin{array}{l}\text { Hemoglobin } \\
(\mathrm{g} / \mathrm{L})\end{array}$ & 8.2 & 10 & 9.6 & 11 & $11.5-15.5$ \\
$\begin{array}{l}\text { Bilirubin, total } \\
(\mathrm{mg} / \mathrm{dl})\end{array}$ & 16.3 & 5.13 & 1.92 & 1.3 & $0.2-1.0$ \\
$\begin{array}{l}\text { Bilirubin, } \\
\text { conjugated } \\
(\mathrm{mg} / \mathrm{dl})\end{array}$ & 6.9 & 3.27 & 1.13 & 0.5 & $<0.35$ \\
$\begin{array}{l}\text { Aspartate } \\
\text { aminotrans- }\end{array}$ & 28 & & & & $15-40$ \\
$\begin{array}{l}\text { ferase } \\
(\mathrm{U} / \mathrm{L})\end{array}$ & 336 & 113 & 60 &
\end{tabular}




\begin{tabular}{|c|c|c|c|c|c|}
\hline $\begin{array}{l}\text { laboratory } \\
\text { investigations }\end{array}$ & Day 1- admission & $\begin{array}{l}\text { Day } 14 \text { - } \\
\text { Rifampin } \\
\text { withdrawn }\end{array}$ & $\begin{array}{l}\text { Day } 23 \text { - } \\
\text { D-penicillamine } \\
\text { started }\end{array}$ & $\begin{array}{l}\text { Day } 40 \text { - } \\
\text { discharge }\end{array}$ & Reference range \\
\hline $\begin{array}{l}\text { Alanine } \\
\text { aminotrans- } \\
\text { ferase } \\
(\mathrm{U} / \mathrm{L})\end{array}$ & 25 & 237 & 89 & 40 & $10-36$ \\
\hline $\begin{array}{l}\text { Alkaline } \\
\text { phosphatase } \\
(\mathrm{U} / \mathrm{L})\end{array}$ & 29 & 158 & 137 & 114 & $30-120$ \\
\hline $\begin{array}{l}\text { Prothrombin } \\
\text { time }(\mathrm{sec})\end{array}$ & 18.3 & 28 & 40 & 22 & $12.2-15.5$ \\
\hline $\begin{array}{l}\text { International } \\
\text { normalized } \\
\text { ratio }\end{array}$ & 1.2 & 1.9 & 2.6 & 1.5 & $0.8-1.2$ \\
\hline $\begin{array}{l}\text { Platelet count } \\
(/ \mathrm{mm} 3)\end{array}$ & $249 \times 10^{3}$ & $320 \times 10^{3}$ & $343 \times 10^{3}$ & $182 \times 10^{3}$ & $150-450 \times 10^{3}$ \\
\hline
\end{tabular}

Table 1: laboratory studies on day 1 of admission compared with $14^{\text {th }}$ day - withdrawn of rifampin, $23^{\text {rd }}$ day -initiation of D-penicillamine and $40^{\text {th }}$ day- discharge.

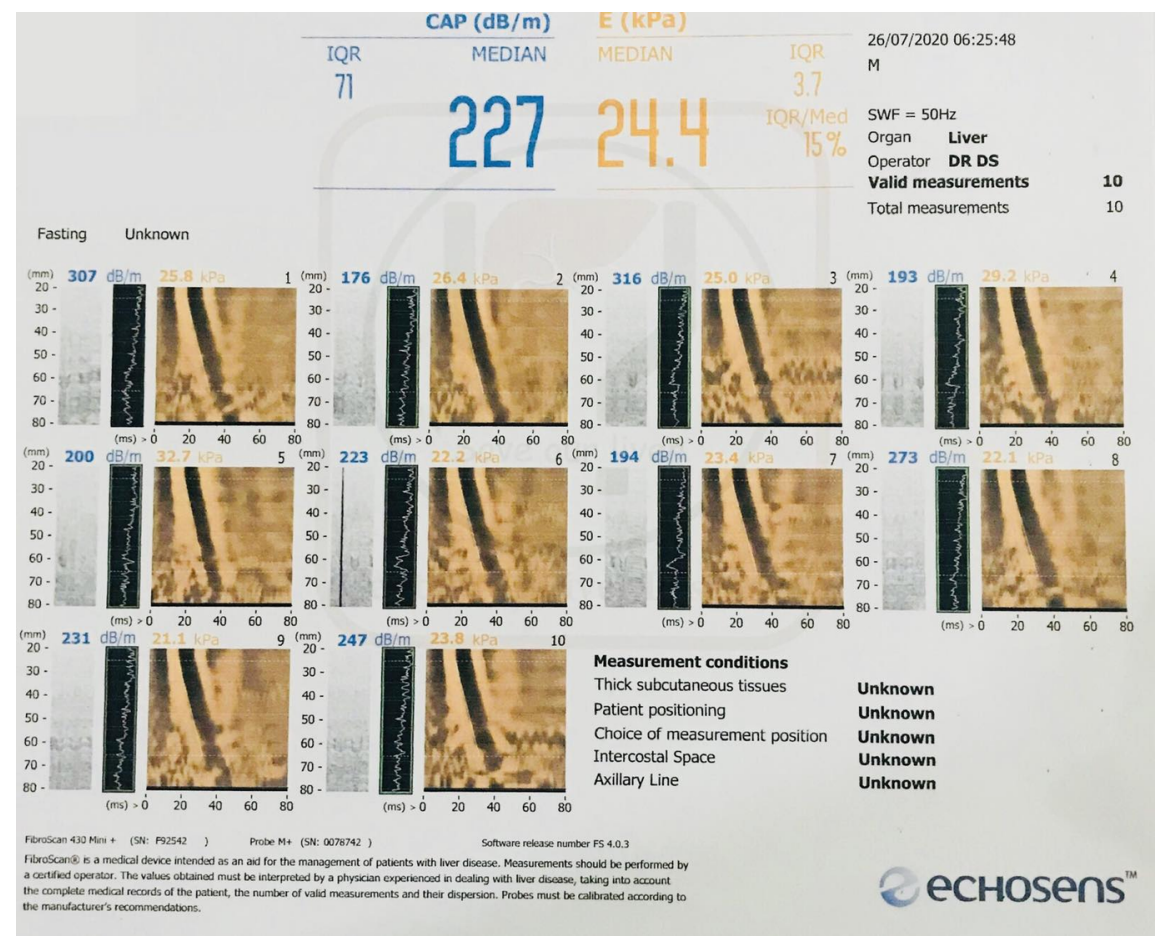

Figure 1: FibroScan of liver showing advanced liver scarring 


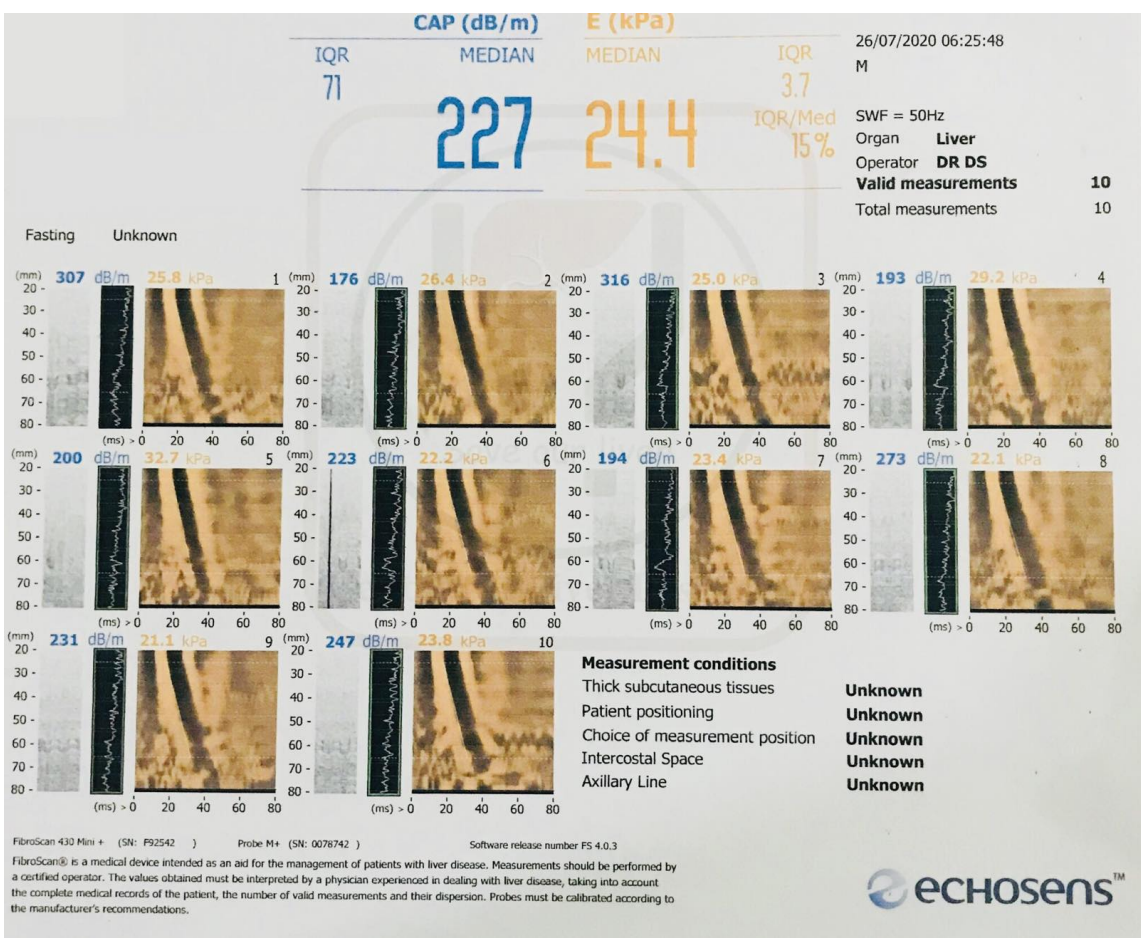

